\title{
CARBON CONTENT, SOLIDIFICATION AND STRAIN ENERGY CONSIDERATIONS DURING CONTINUOUS CASTING OF MICROALLOY STEEL*
}

Steven G. Jansto ${ }^{1}$

\begin{abstract}
Carbon content and continuous casting parameters affecting solidification behavior, such as super heat, mold level fluctuation, heat transfer, fine grain chill zone depth and other process solidification parameters directly influence the surface and internal quality of the steel strand. The carbon content, resultant fine grain chill zone depth, the equiaxed-columnar transition zone and the strain energy are the primary drivers that govern hot ductility behavior. These factors influence the propensity for crack formation during the unbending section in the continuous casting process. Elements such as microalloys exhibit secondary or tertiary root causes for crack formation and are not the primary crack formation root cause. This solidification research identifies that the traditional hot ductility as measured via the percent reduction in area (\%RA) at elevated temperature grossly overstates the minimum ductility required to assure crack-free casting of microalloyed steels. The strain at the ultimate tensile strength exhibits a very high correlation coefficient with strain energy while an extremely low correlation coefficient is exhibited with \%RA.
\end{abstract}

Keywords: Equiaxed-columnar transition zone; Heat flux; Residual strain; Strain energy.

1 Ph.D./Materials Science \& Engineering and Master/Business Administration, Technical \& Market Development Manager, CBMM, Pittsburgh, PA, USA. 


\section{INTRODUCTION}

Microalloy steels play an important product development role within the automotive, energy and structural segments. New and advanced microalloy high strength steel grades are being developed to meet these material challenges. End users are demanding property improvements in the strength-toughness balance for plates and bars. For sheet products, improvements in the strength-formability-stretch flangeability balance are desired. However, often during the continuous casting process, both the internal and surface quality of the billets and/or slabs prevents the successful achievement of this property balance. Often, the chemistry and microalloys and/or alloy composition is incorrectly identified as the root cause of the quality problem. In fact continuous casting process metallurgy parameters, such as superheat, mould level fluctuation, heat transfer, equiaxed-columnar grain (EACLG) transition zone depth are the root cause and will directly influence solidification, hot ductility behavior and hence the surface and internal quality of the steel strand. Also, the one element which has the largest influence of solidification and the resultant microstructure is the carbon. However, if the chemistry is then altered, end user mechanical properties and demands are often not achieved and customer complaints result. Based on the hot ductility behavior of industrial produced heats, it is determined that the traditional hot ductility as measured via the percent reduction in area (\%RA) at elevated temperature grossly overstates the minimum ductility required to assure crack-free casting of microalloy steels. Strain energy and EACLG location is a better measure of the hot ductility behavior than \%RA.

\subsection{Background}

There are several published papers based upon the relevance of the traditional hot ductility trough relationship and lower percent reduction in area (\%RA) associated with higher carbon equivalent steels with and without microalloy additions of $\mathrm{Nb}, \mathrm{V}$ and/or Ti. This extensive research has been performed in an attempt to relate the steel chemistry to the hot ductility behavior of low and medium carbon microalloyed steels $[1,2]$. The early research focus by others has primarily studied the chemistry and optimizing the composition in order to increase the percent reduction in area during the unbending of the continuous cast slab, thereby raising the ductility trough. Although the emphasis on chemistry has been well studied, the steelmaking, solidification dynamics and process metallurgy parameters of the actual steelmaking operations are rarely correlated to the hot ductility behavior and resultant slab surface quality. In addition, most studies involve laboratory produced heats whereas this research is based solely upon industrial produced samples with an emphasis on process parameters and solidification at different carbon levels.

The relationship between the carbon level of the steel and heat transfer rate conditions for solidification affects the solidified microstructure, the thickness of the equiaxed chill zone and its resistance to crack formation. At some distance below the surface where the chill zone ends, there exists an equiaxed columnar grain transition zone (EACLG). This zone is a mixed grain microstructure and hence, a zone of high residual strain. On the opposite end of the EACLG transition zone there exists the initiation of the columnar grain microstructure. The closer the EACLG transition zone is to the surface then the probability of the mixed grain generating a crack through the unbending section of the caster increases regardless of the microalloy content. Certainly, the carbon content has a huge influence. The measure of \%RA as a 
correlation to the propensity for cracking during casting is very weak. This study shows that the reason for this lack of correlation is due to the relationship between the steelmaking and caster operation affecting solidification and the depth of the equiaxed chill zone. It is proposed and validated through this study that the strain energy is a better measure of predicting the hot ductility behavior during the continuous casting of slabs rather than the \%RA measurement. Also, close evaluation of the shape of the stress strain curve is vital and can inherently compare both the elastic and plastic strain behavior. This approach is new and brings a different viewpoint and methodology for better prediction of hot ductility behavior based upon industrial cast sample and not laboratory heats which do not correlate to the EACLG transition zone.

\subsection{Unbending section of caster and imposed unbending section stress on Equiaxed Columnar Grain (EACLG) Transition Zone}

The unbending section of the continuous caster imposes the highest strain on the solidifying section of the slab or billet as it is processed. The strain is directly related to the metallurgical radius of the caster which varies from mill to mill and the casting speed. The smaller the metallurgical radius (i.e. curvature of the bend) then the higher the imposed strain on the solidifying strand. Figure 1 below illustrates the location of the unbending section of the caster and high induced strain region.

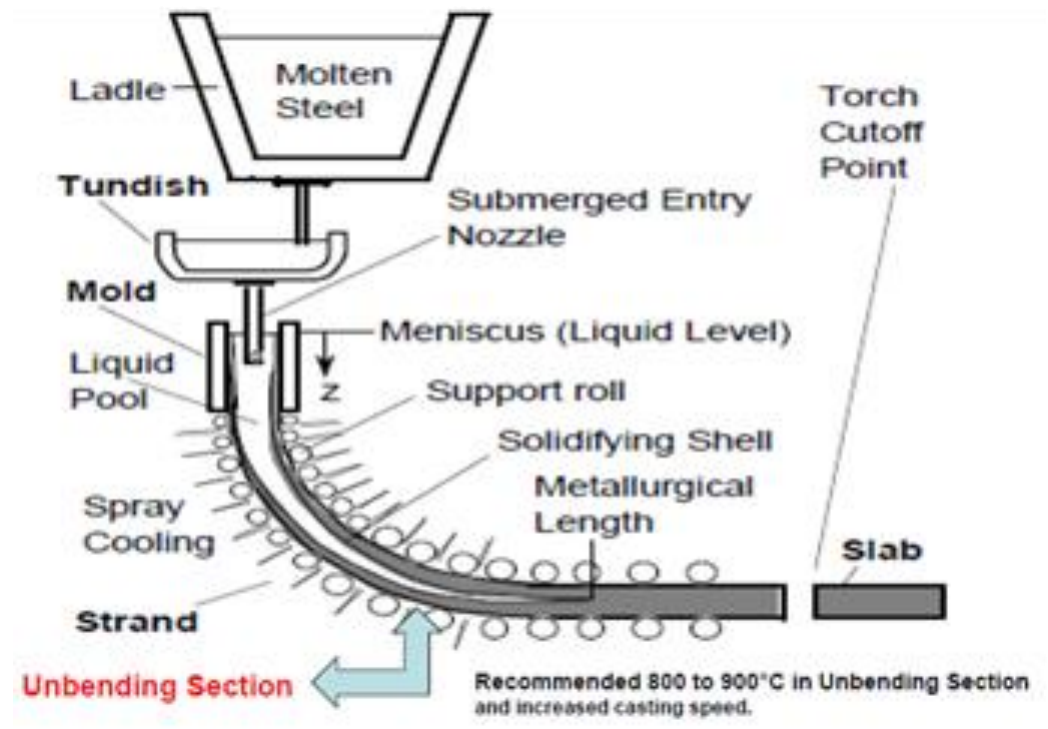

Figure 1. Unbending section of continuous caster.

Since the typical temperature through the unbending section of the caster is between 700 to $950^{\circ} \mathrm{C}$, most of the hot ductility \%RA research has been studied in this temperature range. The hot tensile tests (\%RA) are performed within this temperature range at strain rates between 0.001 to $0.0001 \mathrm{~mm} / \mathrm{mm} / \mathrm{second}$ and is evaluated as well for this stress-strain curve hot tensile test analysis. This strain rate simulates the strain rates induced within the unbending section of industrial casters at typical casting speeds for microalloy steels. The ductility trough in this example is typically between the $750-800^{\circ} \mathrm{C}$ through the unbending section with approximately $20-25 \% R A$ at strain rates of 0.0001 to $0.001 \mathrm{~mm} / \mathrm{mm} / \mathrm{sec}$. Most industrial casters 
operate at casting speeds through the straightening section with a strain rate during unbending between 0.0001 to $0.001 \mathrm{~mm} / \mathrm{mm} / \mathrm{sec}$ strain rate.

The Equiaxed Columnar Grain transition zone (EACLG) is defined as the depth below the surface of the cast strand where the equiaxed chill zone transitions into the columnar zone. The typical microstructure is observed through a macroetch of the cross section of a continuous slab or billet to measure the depth at which this transition zone exists. This zone represents a variable grain size due to the transition from equiaxed to columnar grains and a high residual strain region exists due to the mixed grain microstructure. Upon solidification, the equiaxed chill zone is usually between 10 to $25 \mathrm{~mm}$ in thickness depending upon the slab thickness being cast, casting speed, primary cooling rate and the associated heat transfer. Figure 2 below illustrates a typical macroetch.

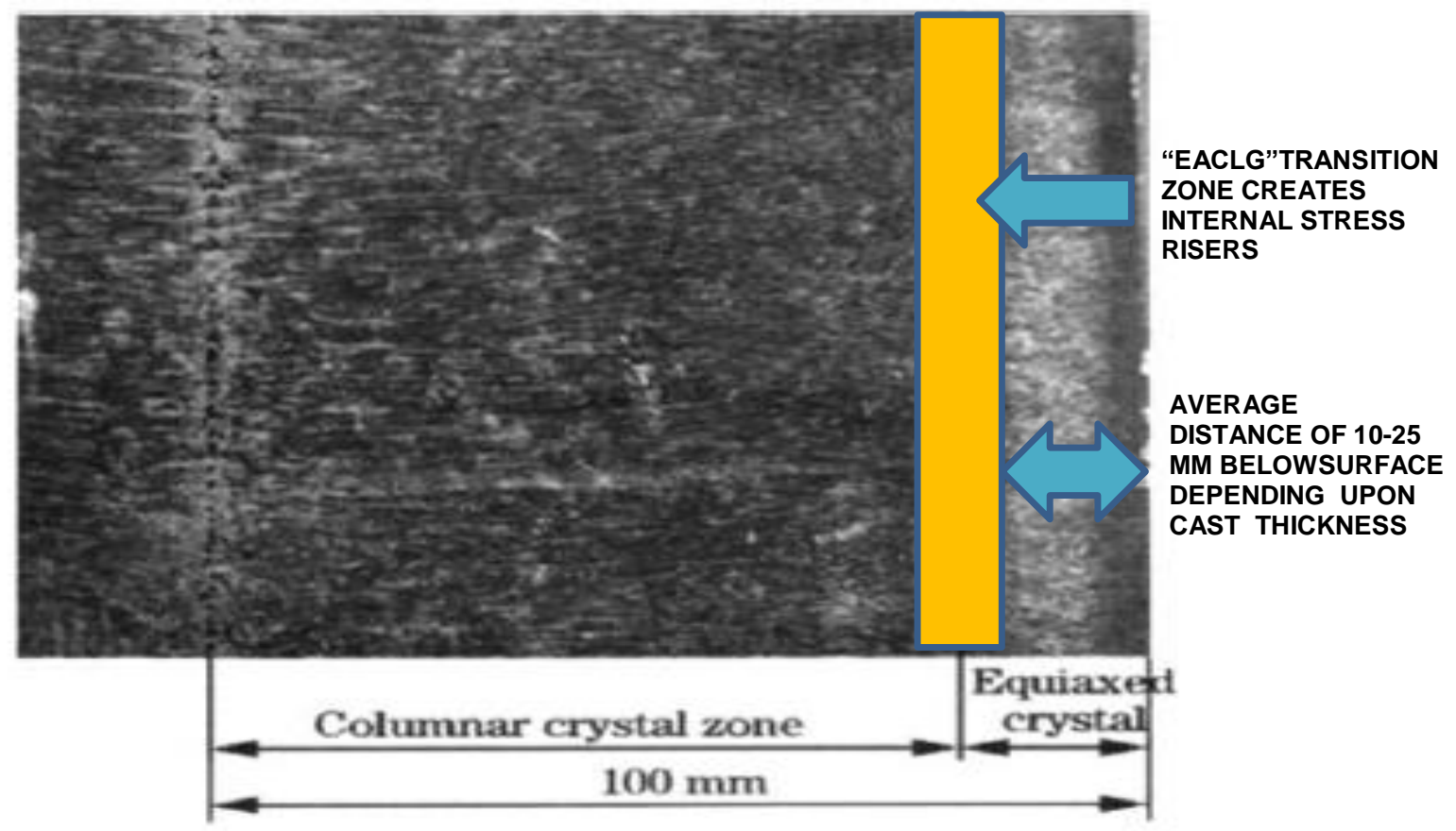

Figure 2. Equiaxed columnar transition zone.

This quality control methodology is fundamental to any mill producing world class steels whether simple C-Mn, micoralloyed $\mathrm{V}-\mathrm{Nb}-\mathrm{Ti}$ and $\mathrm{B}$ steels and/or heavily alloyed Cr-Ni-Mo-Cu steels.

\subsection{Crack initiation and propagation in unbending section and downstream}

Fundamentally it is globally accepted that numerous continuous cast initiated cracks appear below the surface. This phenomenon is the reason why for decades there has been oxygen scarfing and/or billet/slab grinding operations such that the equiaxed grain surface layer is removed so the slab or billet could be visually observed and inspected for cracks. In many cases, the EACLG is macroscopically revealed and removed. Now with the successful removal of the layer shown in Figure 2 , the sub-surface integrity is exposed with columnar grains. The evaluation of the stress strain behavior of the EACLG transition is critical. Thus, samples were extracted from this transition zone and hot tensile tests and stress-strain curves were evaluated. 
From the time the solidifying skin initially forms in the mold until after solidification is complete, a continuously cast section is subjected to a complex history of thermal and mechanical stresses. These conditions are extremely difficult to simulate under laboratory conditions. Also, in most casting machines severe bending deformations are imparted to the cast strand, thus some designs either introduce or eliminate a curvature on vertical curved or plain curved caster. The ability of the solidified material to withstand these stresses and strains is essential in permitting the casting operation to proceed smoothly.

\subsection{Heat flux and carbon content relationship}

Carbon exhibits the largest effect on the mould heat transfer rate (i.e. flux). The relationship between carbon content and heat flux is quite often overlooked when performing root cause analysis of continuous cast cracks. There has been an overabundance of references regarding the ferrite formation and weak grain boundaries [3], precipitation of microalloy carbides and nitrides [4] and low \%RA [5] from hot ductility tensile tests at unbending temperatures. Figure 3 illustrates the relationship between carbon content and the average mould heat transfer rate.

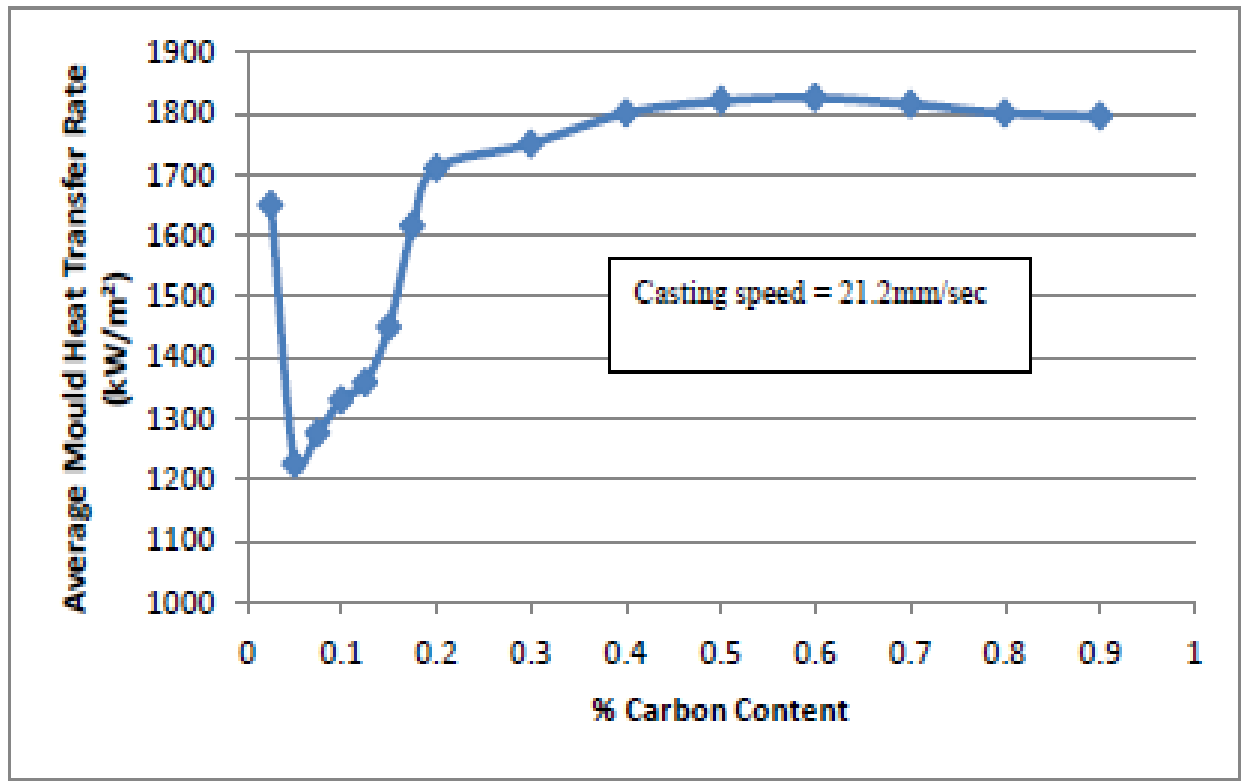

Figure 3. Average mould heat flux versus carbon content [6]

The steel chemistry affects the heat flow rates up to $0.25 \% \mathrm{C}$ and is then essentially invariant above $0.25 \% \mathrm{C}$ to $0.90 \% \mathrm{C}$. The mould heat flux is near a minimum between 0.05 to $0.10 \% \mathrm{C}$. The steep slope of the average heat transfer rate occurs between 0.025 and $0.050 \% \mathrm{C}$ decreases approximately $37 \%$ from 1650 to $1210 \mathrm{~kW} / \mathrm{m} 2$. However, between 0.050 and $0.100 \% \mathrm{C}$ the average heat transfer rate increases only approximately $8 \%$ and is thus, easier to control with the primary cooling section in the caster compared to the 0.025 to $0.050 \% \mathrm{C}$ range. At $0.100 \% \mathrm{C}$, Brimacombe and Grill [7] endorsed the mechanism based upon the $\delta$ - $\gamma$ phase transformation to explain the roughest internal ripples in the sub-surface of the skin. 


\section{MATERIAL AND METHODS}

Hot tensile tests were performed on a Gleeble 3500 thermomechanical system. The industrial steel samples were heated to $1300^{\circ} \mathrm{C}$ at a heating rate of $10^{\circ} \mathrm{C} / \mathrm{sec}$ and held for 5 minutes to assure that the microalloy precipitates went back into solution. The cooling rates are at $60^{\circ} \mathrm{K} /$ minute to the test temperature which simulates the actual casting conditions through the unbending section of the industrial casters from which the steel samples with the EACLG transition zones were obtained. Thermocouples on this unit provide signals for accurate feedback control of specimen temperatures. Specimens are clamped securely and tightened by hand in the test chamber of the Gleeble 3500 thermo-mechanical tester. The machined EACLG specimens are seated between two water-cooled copper jaws located nearby the specimen threads. Test temperatures were between 700 to $950^{\circ} \mathrm{C}$ to simulate straightening (unbending) temperatures at the industrial casters who provided samples. Strain rates simulated the actual operational strain rate at the caster (i.e. between 0.001 and $0.0001 \mathrm{~mm} / \mathrm{mm} / \mathrm{second}$ ). All hot tensile tests were performed on a Gleeble 3500 model. Figure 4 below schematically presents the heating and cooling schedule for an $800^{\circ} \mathrm{C}$ test temperature example.

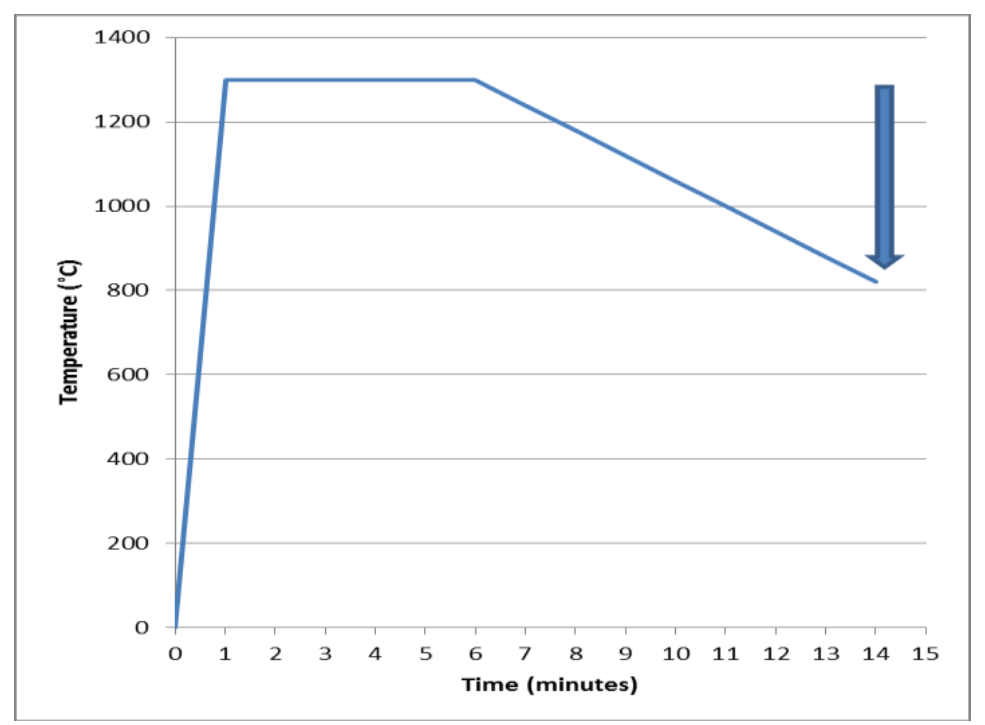

Figure 4. Heating \& cooling schedule example for $800^{\circ} \mathrm{C}$ test at two strain rates $(0.001 \mathrm{~mm} / \mathrm{mm} / \mathrm{sec}$ and $0.0001 \mathrm{~mm} / \mathrm{mm} / \mathrm{sec}$ ).

A variety of steel grades ranging from $0.045 \% \mathrm{C}$ to $0.411 \% \mathrm{C}$ with varying alloy and microalloy contents were obtained directly off the industrial caster. Especially important in this research is the comparison of the stress strain curves for the peritectic grades and the influence of the thinner equiaxed chill zone in the peritectic grades regardless of the microalloy content. The chemistry of the steels evaluated is shown below in Table 1. 
Table 1. Steel grade chemistries

\begin{tabular}{ccccccccccccccc}
\hline ID & $\mathrm{C}$ & $\mathrm{Mn}$ & $\mathrm{Si}$ & $\mathrm{Nb}$ & $\mathrm{V}$ & $\mathrm{Ti}$ & $\mathrm{Mo}$ & $\mathrm{G}$ & $\mathrm{Cu}$ & $\mathrm{Ni}$ & $\mathrm{Al}$ & $\mathrm{S}$ & $\mathrm{P}$ & $\mathrm{N}$ \\
\hline 1A & .158 & 1.45 & .454 & .041 & .009 & .004 & .004 & .048 & .019 & .046 & .033 & .002 & .013 & .0058 \\
\hline 2A & .154 & 1.45 & .455 & .042 & .009 & .005 & .006 & .053 & .027 & .050 & .033 & .001 & .014 & .0027 \\
\hline 3B & .074 & 1.55 & .209 & .050 & .073 & .019 & .005 & .046 & .035 & .049 & .035 & .002 & .009 & .0040 \\
\hline 4C & .132 & 1.57 & .260 & .036 & .079 & .031 & .005 & .046 & .015 & .041 & .035 & .002 & .008 & .0058 \\
\hline 5D & .411 & 1.68 & .210 & .002 & .090 & .017 & .004 & .053 & .024 & .046 & .033 & .007 & .013 & .0061 \\
\hline 6E & .141 & 1.39 & .390 & .040 & .078 & .009 & .006 & .047 & .026 & .045 & .029 & .004 & .011 & .0062 \\
\hline $7 \mathrm{~F}$ & .142 & 0.61 & .640 & .002 & .007 & .005 & .497 & 1.41 & .016 & .059 & .039 & .001 & .008 & .0083 \\
\hline 8G & .253 & 1.05 & .503 & .002 & .008 & .028 & .184 & .387 & .016 & .369 & .044 & .002 & .009 & .0052 \\
\hline 9H & .072 & 1.49 & .250 & .036 & .008 & .015 & .004 & .044 & .142 & .382 & .036 & .002 & .009 & .0056 \\
\hline $10 \mathrm{l}$ & .081 & 0.99 & .205 & .002 & .010 & .028 & .006 & 1.05 & .022 & .063 & .036 & .004 & .010 & .0047 \\
\hline 11 & .072 & 1.41 & .189 & .023 & .010 & .014 & .007 & .053 & .023 & .051 & .035 & .005 & .011 & .0051 \\
\hline $12 \mathrm{~K}$ & .147 & 1.40 & .377 & .010 & .009 & .005 & .007 & .067 & .033 & .072 & .039 & .002 & .011 & .0041 \\
\hline $13 \mathrm{~L}$ & .045 & 1.90 & .179 & .084 & .013 & .098 & .006 & .042 & .045 & .051 & .026 & .002 & .008 & .0063 \\
\hline
\end{tabular}

\section{RESULTS AND DISCUSSION}

The strain rates for all of the tests simulated the actual operational strain rate at the unbending section of the casters' providing the samples for this study. The two strain rates employed were between 0.001 and $0.0001 \mathrm{~mm} / \mathrm{mm} / \mathrm{second}$. The raw data output of force, dynamic gauge measurements, stress and strain were converted into a stress strain curve for each sample. Figure 5 is an example for one chemistry which illustrates the stress strain curve at $800^{\circ} \mathrm{C}$ for a $0.1 \% \mathrm{C}-1.45 \% \mathrm{Mn}$ and $0.04 \% \mathrm{Nb}$ chemistry at 0.0001 and 0.001 strain rates.
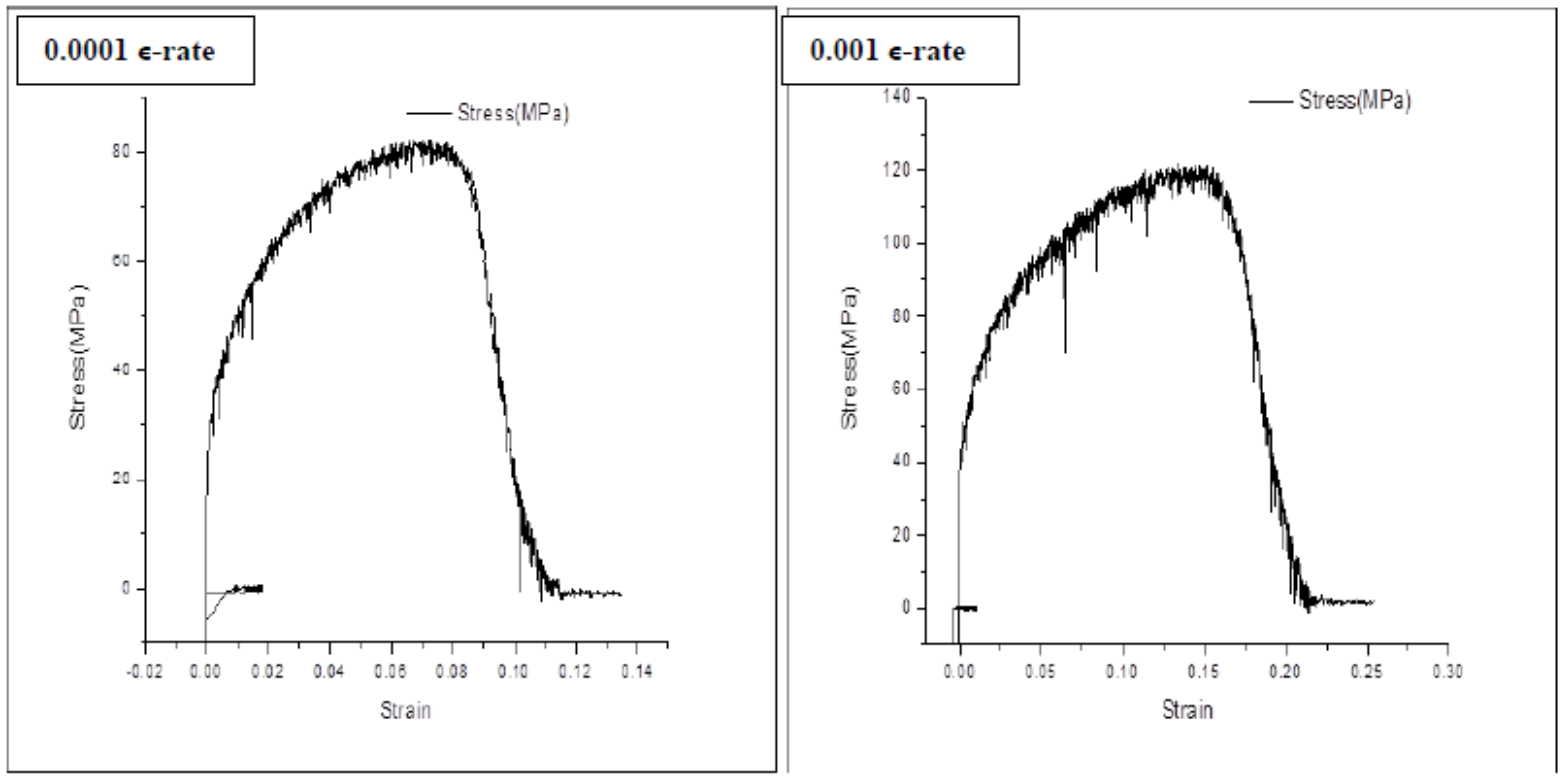

Figure 5. Stress strain curve (sample $1 \mathrm{~A}$ at $800^{\circ} \mathrm{C}$ and 0.0001 (left) \& 0.001 strain rate (right). 
Note that at the higher strain rate, the ultimate tensile strength is $120 \mathrm{MPa}$ versus $80 \mathrm{MPa}$ (at the lower strain rate) and 0.155 strain versus 0.068 strain at UTS respectively. The strain at fracture for the 0.001 strain rate is 0.254 versus 0.135 for the lower strain rate of 0.0001 . The area under the $\sigma-\varepsilon$ curve up to a given value of strain is defined as the total mechanical energy per unit volume $\left(U^{*}\right)$ consumed by a material in the process of straining to that given value. The strain energy equation is shown by:

$$
U^{*}=1 / V \int P d L=\int_{0}^{L}\left(P / A_{0}\right)\left(d L / L_{0}\right)=\int_{0}^{\varepsilon} \sigma d \varepsilon
$$

In the absence of slip and other mechanisms for energy dissipation, this mechanical energy is stored reversibly within the material as strain energy. The strain energy increases quadratically with the stress or strain (i.e. as the strain increases then the energy stored by a given increment of additional strain grows as the square of the strain). The area up to the yield point is termed the modulus of resilience. The total area up to fracture is termed the modulus of toughness. All of the samples described in Table 1 were tested at temperatures between 700 to $950^{\circ} \mathrm{C}$ at two strain rates which emulated the unbending strains at the industrial caster. Table 2 below presents the hot ductility data at $800^{\circ} \mathrm{C}$ near the base of the hot ductility trough for the traditional \%RA and the strain energy.

Table 2. Percent reduction in area and strain energy comparison

\begin{tabular}{|c|c|c|c|c|c|c|c|}
\hline Sample ${ }^{*}$ & $\begin{array}{l}\text { Casting } \\
\text { Speed } \\
(\mathrm{m} / \mathrm{min})\end{array}$ & $\begin{array}{l}\text { SE at } \\
800^{\circ} \mathrm{C} \\
0.001\end{array}$ & $\begin{array}{l}\text { SE at } \\
800^{\circ} \mathrm{C} \\
0.0001 \\
\end{array}$ & $\Delta_{\mathrm{SE}}$ & $\begin{array}{l}\% \text { RA at } \\
800^{\circ} \mathrm{C} \\
0.001\end{array}$ & $\begin{array}{l}\% \text { RA at } \\
800^{\circ} \mathrm{C} \\
0.0001\end{array}$ & $\Delta_{\mathrm{RA}}$ \\
\hline $1 \mathrm{~A}$ & 1.16 & 19.381 & 6.663 & 12.718 & 27.6 & 14.5 & 13.1 \\
\hline $2 A$ & 1.16 & & 11.466 & & 43.3 & 21.4 & 21.9 \\
\hline $3 B$ & 1.22 & 41.269 & 22.931 & 18.338 & 48.9 & 33.9 & 15.0 \\
\hline $4 C$ & 1.16 & 58.142 & 44.564 & 13.688 & 68.1 & 58.0 & 10.1 \\
\hline $5 \mathrm{D}$ & 1.35 & 46.489 & & & 70.7 & & \\
\hline $6 \mathrm{E}$ & 1.16 & 27.291 & 8.375 & 18.916 & 38.0 & 20.1 & 17.9 \\
\hline $7 F$ & 1.17 & 21.927 & 12.742 & 9.185 & 46.9 & 38.5 & 8.4 \\
\hline $8 \mathrm{G}$ & 1.16 & 37.986 & & & 85.2 & & \\
\hline $9 \mathrm{H}$ & 0.89 & 38.886 & & & 47.9 & & \\
\hline $10 \mathrm{I}$ & 1.35 & 52.427 & 24.554 & 27.873 & 73.5 & 61.4 & 12.1 \\
\hline $11 \mathrm{~J}$ & 1.09 & 40.695 & 18.760 & 21.935 & 59.2 & 45.1 & 14.1 \\
\hline $12 \mathrm{~K}$ & 1.16 & 23.372 & 8.404 & 14.968 & 39.4 & 24.1 & 15.3 \\
\hline $13 \mathrm{~L}$ & 1.18 & 12.270 & 4.094 & 8.176 & 15.0 & 11.4 & 3.6 \\
\hline
\end{tabular}


Steel shell growth in a continuous casting mould is substantially influenced by carbon content in steel. Shell deformation occurs as a consequence of shell shrinkage due to thermal contraction from the delta phase to ferrite phase transformation during initial solidification. This deformation induces the surface roughness of the shell, resulting in anomalous decrease of heat transfer rate from a shell to a mold, often causing uneven shell growth and surface crack in the shell. Note that the effect of the C-content adds another differential higher order variable into the process. The peritectic transformation supports large austenitic grains resulting in brittle material behavior during solidification. That means, in a temperature range between $\mathrm{Ae} 3$ and approximately $1100^{\circ} \mathrm{C}$, the solidified shell material can easily be damaged and a crack growth along the grain boundaries if the EACLG transition zone is near the surface as the strand passes through the unbending section of the caster. Additionally, high stresses are introduced during the early stage of solidification. A strong shrinkage takes place during the phase change from the $\delta$-ferrite to the tighter arranged $\gamma$-austenite structure [8]. Hypo-peritectic grades often result in unstable operating conditions (mould level hunting, casting breakouts) and defective slab products (i.e. rough surface and deep oscillation marks) and surface cracks both in longitudinal and transversal direction.

\subsection{Stress Strain Curve and Percent Reduction in Area Correlation}

The steels tested in this study exhibited a range of \%RA data that were considerably lower than the published $40 \%$ minimum \%RA required for crack-free casting of $\mathrm{Nb}$ bearing steels [9]. Yet, these steels did not exhibit cracks. Thus, the strain energy (SE) has been introduced to assist in ascertaining the hot ductility behavior of steels. It is postulated that the stress strain curve is a more accurate measure for a given steel's hot ductility behavior than a simple measurement of the \%RA. In order to test this postulation, all of the \%RA and strain energy data was plotted against ultimate tensile strength and strain at ultimate tensile strength. Figures 6 and 7 compare the strain energy and \%RA as a function of the strain at the ultimate tensile strength.

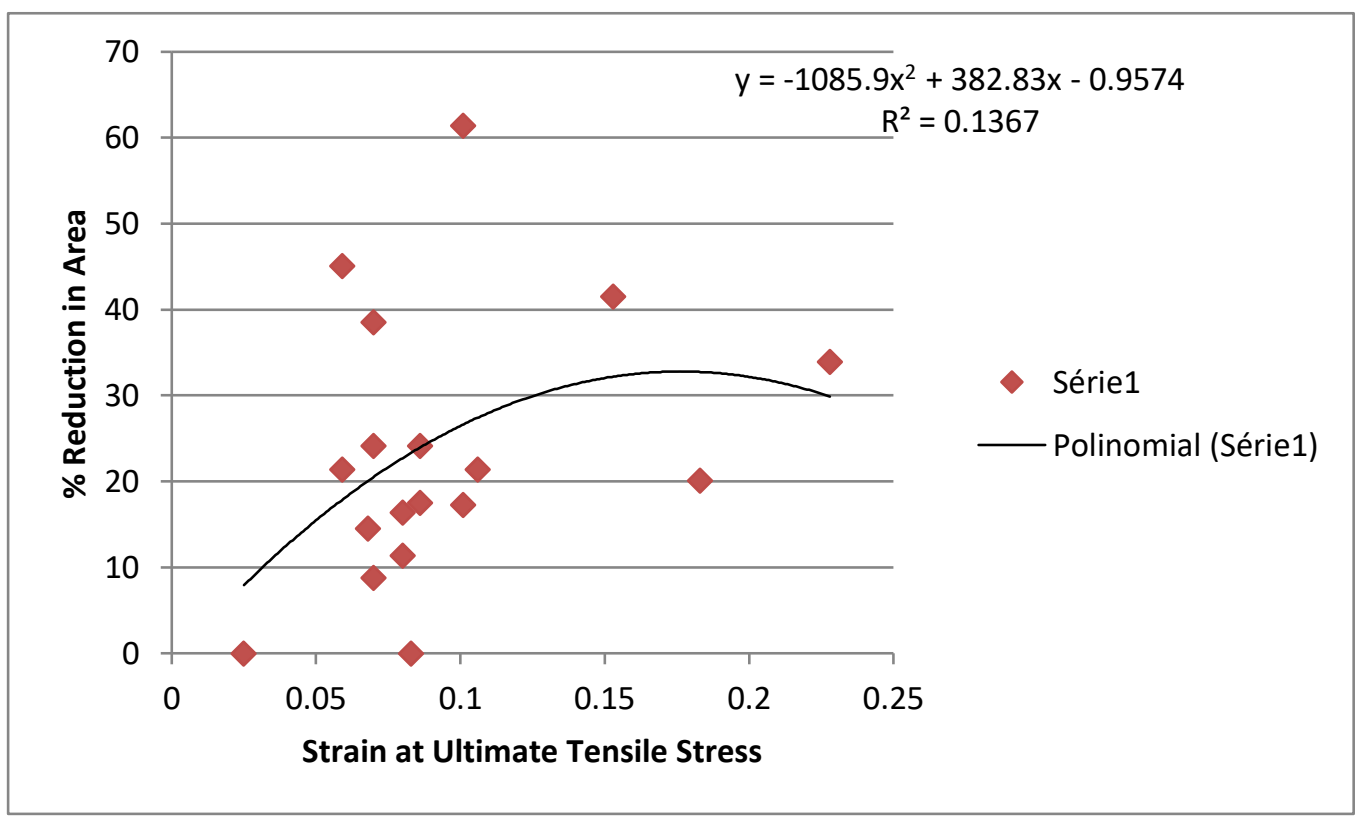

Figure 6. Percent reduction in area versus strain at the ultimate tensile strength (UTS) 


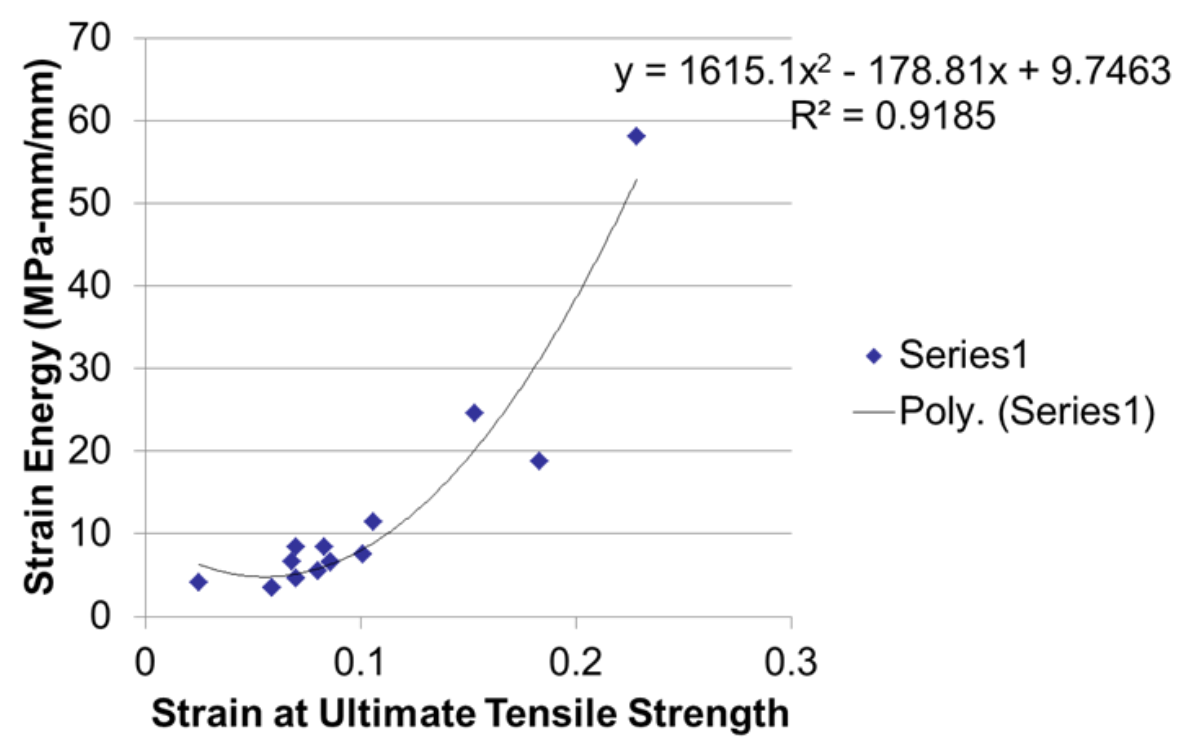

Figure 7. Strain energy versus strain at the ultimate tensile strength (UTS)

A strong correlation coefficient R-squared of 0.906 was determined between the strain energy and strain at the ultimate tensile strength and only $0.1367 \mathrm{R}$-squared between the \%RA and the strain at UTS as shown in Figure 6 and 7. The key factor affecting the subsurface crack propagation at the EACLZ will be the tolerable strain at the UTS. The strain at UTS is related to the thickness of the equiaxed chill zone and the depth of the EACLG transition zone below the surface. As a result of the higher correlation for both the ultimate tensile strength and the strain, it is proposed that the strain energy be defined as the preferred measure of the hot ductility characterization for different microalloy compositions. It also reinforces the conclusion that hot ductility behavior and propensity for cracking is governed by the solidification phenomena. Future researchers are encouraged to report strain energy data when performing hot ductility tensile tests at temperature. Hence, a global strain energy database should be compiled in order to further expand. Reasons for the poor strain correlation with \%RA is related to process metallurgical factors and solidification behavior which are typically not considered in hot tensile testing and $\%$ RA determination.

Based upon this reported minimum 40\%RA [9] for crack-free casting, the implications have resulted in some alloy developers reducing or totally eliminating the selection of $\mathrm{Nb}$ for a new carbon steel development due to this published $40 \% \mathrm{RA}$ minimum casting criterion. Yet based upon actual operational experience and this hot ductility study, \%RAs as low as $10 \%$ will result in crack-free casting of Nb-bearing steels at industrial casters around the world.

\subsection{Development of Strain Energy Management at Caster}

Development of the database at a given mill that will relate the cast grain microstructure to the strain at the ultimate tensile strength is quite valuable and relatively simple to attain. Listed below is the standard operating practice:

1) Cut slab or billet samples off the caster and record all process metallurgy data 
2) Slice a thin cross section and macroetch the slab or billet (as shown in Figure 2) and measure; a) the equiaxed chill zone thickness, b) the thickness of the mixed grain transition zone and $c$ ) the thickness below the surface where the EACLG transition zone ends on all four sides.

3) Conduct hot tensile tests at $700^{\circ}, 750^{\circ}, 800^{\circ}, 850^{\circ}$ and $900^{\circ} \mathrm{C}$ at two strain rates of 0.001 and $0.0001 \mathrm{~mm} / \mathrm{mm} / \mathrm{sec}$. Samples should be from the EACLG zone identified from the macroetch test.

4) Evaluate the stress strain curve for the yield and tensile and fracture strength and strain at ultimate tensile strength.

5) Integrate the area under the stress strain curve and calculate the strain energy.

6) Compare \% reduction in area.

7) Since the process metallurgy variables during casting are measured, begin the correlation of the macroetch grain size and depth data to the strain at the UTS to surface quality observation of the slab or billet (i.e. cracks or no cracks).

\section{CONCLUSIONS}

The analysis of the stress strain behavior and strain energy and \%RA data has been related to the steelmaking and continuous casting process metallurgy principals. The hot ductility and solidification behavior was studied in relation to the chemical composition, process metallurgy variables and hot ductility behavior for a variety of microalloy and non-microalloy steel chemistries. The carbon content has the largest effect on the internal mould heat extraction rate. Microalloys and other alloys have a minor effect on the inherent heat transfer rate.

All samples in this study were obtained from industrial operations. Percent RA has been the traditional assessment tool to characterize the hot ductility behavior and potential propensity for cracking through the unbending section of the caster. This study introduces the strain energy and the equiaxed columnar grain (EACLG) transition zone size and location as a measure for hot ductility behavior assessment and propensity for cracking. The strain energy exhibits a stronger correlation coefficient to the strain at the UTS than with \%RA.

This research has determined that the published minimum required \%RA for crackfree casting is inaccurate and significantly overstates the \%RA required for crack-free castability. The literature quotes $40 \%$ RA minimum for Nb-bearing steels when in fact as low as $10 \%$ minimum RA is more than sufficient to assure crack-free casting based upon the extensive testing, operational parameter review and microstructure EACLG analysis performed in this study.

In conclusion, strain energy is recommended to evaluate hot ductility behavior. It is concluded that strain energy and measurement of the EACLG is a better methodology for evaluation of the hot ductility behavior than \%RA. There is considerable value in the evaluation of the hot stress and strain curves, solidification microstructure, process metallurgy parameters and their relationship to slab quality instead of just basing hot ductility on simple \%RA measurement.

\section{REFERENCES}

1 Ouchi C. Matsumoto A. Hot Ductility in Nb-Bearing High Strength Low-Alloy Steels. Transactions ISIJ. 1982;22;181-189.

2 Mintz B. Crowther DN. Hot Ductility of Steels and Its Relationship to the Problem of Transverse Cracking in Continuous Casting. International Materials Reviews. 2010:55 (2);168-196. 
3 Mintz B. Cowley A. Deformation Induced Ferrite and Its Influence on the Elevated Temperature Tensile Flow Stress/Elongation Curves of Plain C-Mn and Nb Containing Steels. Material Science Technology. 2006:22; 279- 292.

4 Crowther DN. Mohamed Z. Mintz, B. Influence of Microalloying Additions on the Hot Ductility of Steels Heated Directly to the Test Temperature. Transactions Iron and Steel Institute of Japan. 1987:27(5); 366-375.

5 Wilber GA., et. al. The Effects of Thermal History and Composition on the Hot Ductility of Low Carbon Steels. Metallurgical Transactions. 1975:6A; 1727-1735.

6 Singh SN. Blazek KE. Heat Transfer and Skin Formation in a Continuous Casting Mold as a Function of Carbon Content. Open Hearth Proceedings AIME.1977: 60.

7 Grill A. Brimacombe JK. Influence of Carbon Content on Rate of Heat Extraction in the Mould of a Continuous-Casting Machine. Ironmaking and Steelmaking. 1976: 3(2); 76 79.

8 Mondragon JR. Trejo MH. Roman C. Solist H. Description of the Hypo-peritectic Steel Solidification Under Continuous Cooling and Crack Susceptibility. ISIJ Int. 2008;48: 454460.

9 Mintz B. Importance of Ar3 Temperature in Controlling Ductility and Width of Hot Ductility Trough in Steels and its Relationship to Transverse Cracking. Materials Science Technology.1996:12; 132-138. 